\title{
CHAPTER THIRTY-THREE
}

\section{A REFLECTION}

This part of the study is aimed at the only historical investigation into the opium victim problem. It seems logical that it leads to the following reflection.

From the very beginning of this History of The Opium Problem, we have been confronted with its basic complexity, which it never lost. This complexity could never be reduced to a personal problem of one person or victim. This has many, rather important consequences.

This means directly, for instance, that scholarly disciplines like medical or psychological sciences are not very helpful for understanding, let alone solving the Opium Problem. I do not imply that medical "facts" can be left out of consideration, as is not done in this History either: see 2.4; 3.1; 3.4 and so on. They are a substantial part of The Problem itself, certainly for the 19th-century Western opium history.

At least for analytical purposes, therefore, we should always perceive this Opium Problem as an externally induced problem: it originates from outside and then develops into something.

If personalized, this perception is important for the following reasons: neither a victim's problem nor an addict's problem can be solved from "inside" the victim or addict (probably only the "side-effects"). In the treatment of addicts and victims, we encounter the same "internal myth", when opium addiction is expected to be treated by other addictive drugs like cocaine or medicines, or that LSD can help to prevent a concentration camp "syndrome" as if the victim had invented concentration camps in his own mind.

Basically, therefore, medicalization, psycho-treatments, meditation, etc. are useless, largely sources of income for therapists, while in exceptional cases interesting for curing side-effects. The victim's problems should be explained, understood and treated or related to, first and foremost, "actions" in social-cultural or political environments appropriate to the victim or addict, from which some individual treatment should be "derived".

How substantial a part of the Opium Problem this is can be seen in the relation between this medical knowledge and profession and the socio- 
biological approaches invented and implemented in the European and American 19th- and early 2oth-century. The often claimed natural or racial disposition for opium or gambling and other vices of the Asian or the Chinese (laziness of the Javanese!) does not exculpate the Western introduction of opium. The most extreme consequence of this perception is that opium (or cocaine for that matter) is imported and distributed among the people in order to make them work harder and longer (for the boss) or deliver more money for the industry/financiers of for drugsdealers and that victims of this "treatment" are seen as criminals to be locked up or, worst, eliminated as worthless bodies.

In other words: in the treatment of all those externally induced vices on victims or victim-countries, the environment or outside world and its history should be considered of overriding importance rather than of limited value. The success of the collective treatment of the Opium Problem in the largest victim-country, China, after $195^{\circ}$ is that in a political, economic and social way, this treatment was induced. In fact, it was methodologically along the same path as its introduction by the Western states and their criminal smugglers and other dubious supporters. 